is 34 minutes at $100^{\circ}$, and 9 years at $25^{\circ}$ (page 207). An extensive list of references follows.

The third part, by L. C. Behr, dealing with indazoles and condensed systems, is also a good factual summary, providing an insight into the structural problems, and indicating the main lines of research which remain to be followed. References are again very numerous.

Regrettably, with such a wealth of material in one volume, the printing is close, and some of the structural formulae absurdly small. The older generation of chemists would do well to provide themselves with a good handlens !

W. J. BARRY

\section{FIESER'S REAGENTS}

Reagents for Organic Synthesis

By Louis F. Fieser and Mary Fieser. Pp. vii +1457. (New York and London: John Wiley and Sons, Inc., 1967.) $210 s$.

Ever since Louis Fieser's sixty-sixth birthday, two years ago, when his publishers announced the forthcoming publication of this book, we have been waiting eagerly for what promised to be a unique and extraordinarily useful book. The authors set out to list the reagents of organic chemistry, including under this heading catalysts, compounds like $N$-bromsuccinimide in which only part of the molecule is transferred, and compounds like tetraphenylcyclopentadienone in which the whole molecule can be present in the product. Because, when reagent is thus defined, every reaction of organic chemistry has a claim to inclusion, the book is necessarily selective. It is no surprise that in most cases the Fiesers have made the obvious choices of what to leave out.

The authors very largely achieve what they set out to do. In a check of a few reagents we wanted to use recently, we found all but three adequately covered (no purification for amyl nitrite [perhaps the American product needs no purifying], no entry for potassium or sodium cyanide, no entry for dimethylamine). But no one will find everything he wants in a book of this sort; it is a tribute to its success that we found so much and that our failures were so trivial. Indeed, because it is so inclusive that many people are going to become dependent on it, those relatively unusual reagents which have not been included are even likelier than before to get buried.

This book also has the fascination of a good dictionary : setting out to look up one reagent, one is continually waylaid by other absorbing entries, the more arcane the better. I not only came across all sorts of reactions I did not know about, but was continually entertained as $I$ read, and almost found myself reading from cover to cover, no part of a reviewer's brief, I think, with this kind of book.

My one criticism (apart from the price, for which there are no doubt reasons) is that the organization into reagents occasionally leads to fragmentation of things that might be better treated as one topic. I can illustrate this with the example of enamines which appear under several headings: as a protecting group in a hydride reduction, under dibenzoyl peroxide (not indexed under enamines), under morpholinocyclohexene (not indexed), under ozonolysis, under sodium borohydride, under piperidine (not indexed), under pyrrolidnocyclohexene (not indexed), under 1,3dichloro-2-butene (not indexed) and under toluenesulphonic acid. Now the indexing failures are trivial; but in this kind of case an entry under the general heading enamines, rather than under several more specific headings, would do much for an understanding of the usefulness of the class and also afford an opportunity for a brief discussion of, in this example, the relative merits of the pyrrolidine and morpholine enamines. This would, of course, be no small task and I would certainly hesitate to tackle it myself on the scale of the whole book.

This criticism is by way of saying that the book is so useful that one half expects to find everything in it.

IAN Fleming

\section{OBITUARIES}

\section{Professor Francis Bitter}

ON November 21, 1967, the National Magnet Laboratory at the Massachusetts Institute of Technology was rededicated as the Francis Bitter National Magnet Laboratory. Professor Bitter, long a leader in research on magnetism at MIT, died on July 26 in Centerville, Massachusetts, after a protracted illness.

Bitter, born in Weehawken, New Jersey, on July 22, 1902, was the son of Karl Bitter, a well known British sculptor. He attended the Taft School, and received the Bachelor of Science degree from Columbia University in 1924. After spending a year in Berlin, where he attended lectures by Einstein, Planck, and von Laue, young Bitter returned to Columbia, receiving the Ph.D. degree in 1928. In his thesis work he used a large electromagnet while studying the diamagnetic susceptibilities of organic gases, and during two years as a National Research Fellow at the California Institute of Technology, he worked further on magnetic problems under the direction of $\mathbf{R}$. $A$. Millikan. In 1930 he joined the Westinghouse Research Laboratories in Pittsburgh, where he carried out applied research on ferromagnetism.

Bitter spent 1933-34 as a Guggenheim Fellow at the University of Cambridge, where he became interested in Kapitza's work on powerful pulsed magnetic fields. Returning to the United States as an associate professor in the Department of Metallurgy at MIT, he set out to develop magnets which would be capable of producing more intense, constant and uniform fields than had previously been available. He attacked this problem effectively by shifting the large masses of iron previously used in electromagnets from the magnets to the generators from which they obtained power. What came to be known as the Bitter magnet is a solenoid carefully designed to provide rapid heat removal by intimate contact with a large volume of water flowing through its turns. A magnet he designed for Zeeman effect studies in 1938 produced 100,000 Gauss, constant to $1 / 10$ per cent and uniform within the same limits throughout a volume of $10 \mathrm{ml}$.

After serving for five years as a commander in the Naval Reserve, working on magnetic detection of submarines, counter-measures for magnetic mines and operations research, Bitter returned to MIT as a professor of physics, where he became active in research on nuclear magnetism and the optical effects of microwave resonance. He made important contributions to the theory of optical pumping.

Bitter's temperament was an interesting amalgam of the artistic and the scientific. The breadth of his scientific in. terests is indicated by the fact that he was successively professor of metallurgy, of physics and of geology and geophysics. Teaching was one of his favourite occupations, and he was an effective adviser to students, serving as master of Ashdown House at MIT from 1960 to 1965 . He was active in the planning of courses and curricula, and was the author of several textbooks.

A large number of his colleagues, former students and friends gathered to honour his memory at a symposium on magnetism held in connexion with the re-dedication of the laboratory he helped to found.

George R. Harrison 